\title{
Dream-Telling Differences in Psychotherapy: The Dream as an Allusion
}

\author{
Marie-Luise Alder ${ }^{1}$ \\ International Psychoanalytic University (IPU)
}

\section{Introduction}

In everyday conversation dream telling occurs seldom: Bergmann (2000) found in his data of many hours of audio recorded family conversations in natural surroundings not a single dream narration. He assumes that psychotherapy should make dream telling more relevant. In our Conversation Analysis of Empathy in Psychotherapy Process Research (CEMPP) project $^{1}$ data of 45 audio recorded and transcribed psychotherapy sessions from psychoanalysis, psychodynamic and Cognitive Behavioural Therapy (CBT) we only find four dream mentioning and three dream telling. Surprisingly, none of these occur in psychoanalysis. The function of dream telling in psychoanalysis has been summarized and analysed by Mathys (2011). This paper will focus on one dream-telling sequence from a CBT session. Nevertheless, this sequence is of high relevance for psychoanalysis because it supports the idea that dreams can be understood as an allusion to the therapeutic relationship. In this brief paper I would like to demonstrate how a dream can serve as an allusion to a contaminated talk and a disappointment in the therapist. It might be for the first time that this is shown on the basis of empirical data.

\section{Method}

The data analysis is done with conversation analysis (CA) (Sacks \& Jefferson, 1995; Sidnell \& Stivers, 2013). CA focuses on talk in interaction and any implications done by the researcher must be verified by the subsequent talk. With this method one cannot only analyse a conversation turn-by-turn but also focus on conversational trajectories that shed light on an utterance that can only be understood within that context. The application of CA onto psychotherapeutic conversations has proven to be a tool for fine-grained analysis in order to detect the very subtle notions within a psychotherapeutic process (Buchholz \& Reich 2015; Peräkylä et al., 2015; Voutilainen, Peräkylä \& Ruusuvuori, 2011).

1 Correspondence concerning this article should be addressed to Marie-Luise Alder, International Psychoanalytic University (IPU), Stromstr. 2-3. 10555 Berlin, Germany. Email: marie-luise.alder@ipu-berlin.de.

${ }^{1}$ Sponsored by Köhler-Stiftung

Language and Psychoanalysis, 2016, 5 (2), 19-26

http://dx.doi.org/10.7565/landp.v5i2.1558 


\section{Results}

\section{One Dream from a CBT Session - More than just a Dream?}

The dream shown below occurs in a CBT Session. This is the second encounter between a female therapist $(\mathrm{T})$ and female patient $(\mathrm{P})$. The transcripts ${ }^{2}$ shown are an English translation of the original German transcript.

\section{Sequence $\mathbf{X}$}

451 P: I have temporarily I dreamed that I (1) well either I had burned hands and thus

452 I couldn't work at all or I've (--) been somehow (1.1) I don't know in the

453 forest I was (.) naked and in need of help

454 [and] then someone passed by looked at me and left again

455 T: [mhmh]

456 P: .h (-) well like (-) one cannot even help me now;

From the first glance this appears like a normal dream report. It fits to Jörg Bergmann's and Anssi Peräkylä's (2014) findings for psychodynamic sessions: The dream-telling starts with no topical connection, no hesitation or justification, the framing of the telling appears to be the teller's dream ("I have ... dreamed"), the dream is externalised as an event in the past and the teller is displayed as a reliable and unreliable witness ("I had..." vs. "I don't know"). However, even though there seems to be nothing extraordinary about that dream something is striking. It is the placing of that dream-telling. Please note that this dream occurs in minute fourteen! In order to understand the function of that dream, we need to rewind the conversation and start the analysis around seven minutes before that dream telling occurs.

\section{Dream-Telling in CBT}

After a general review of her situation during the past week the patient starts to tell the therapist that she had a dream last night. This is roughly in minute seven in which the whole dream-telling episode starts. Please read the following sequence:

\section{Sequence A}

193 P: .hhh (---) ((coughs)) WELL (-) that was the one thing (1.3) and the other (.) 194 tonight I had a dream

\footnotetext{
2 Please note the following rules to read the transcripts: [Square brackets] indicate an overlap in speech; the (pauses) are captured in round brackets in seconds; a point in a bracket indicates a pause of under 0.25 millisecond; one hyphen (-) in brackets indicates a pause of 0.25-0.50 milliseconds; two hyphens indicate a pause of 0.500.75 milliseconds and three hyphens indicate a pause from 0.75-0.99 milliseconds; a .$h$ means the speaker inhales recognisably; a $(\mathrm{h})$ indicates laughter; superscripted ${ }^{\circ}$ indicate low volume; capital letters indicate HIGH volume; inverted >angle brackets< indicate faster speech and the opposite indicates < faster> speech; any semicolon means a fall in intonation and a question mark a raise in intonation; ((double brackets)) contain transcriber's commentaries.
}

Language and Psychoanalysis, 2016, 5 (2), 19-26 
196 (--)

197 P: $<$ ERM $>(-)$ YES and somehow I thought that this dream [series]

198 T:

199 [now mh]

200 P: [sorry]

$201 \quad(--)$

202 P: .HH ((through teeth)) (---) ${ }^{\circ \circ}$ fingernail ${ }^{\circ \circ}$

203 (1.9)

204 T: will be (.) will [be?

205 P: $\quad[\mathrm{mhm}$

$206 \quad(1.2)$

207 T: okay (--) sorry a(h::) [that was

208 P: $\quad$ [yes that was hurting $\mathrm{e}(\mathrm{h})[\mathrm{e}(\mathrm{h})$

209 T: [yes now its fine again ${ }^{\circ} \mathrm{mhmh}{ }^{\circ}$

The patient is about to tell her thoughts about a dream series (line 197). The therapist interrupts her due to a hurting fingernail (lines 198-202) and directs her attention away from the patient on to her fingernail. At the end of this sequence she reassures that everything is "fine again" (line 209) and she redirects the attention back to the patient. After this rupture she passes on the turn with an indistinct continuer "mhmh" (Fitzgerald, 2013). This causes a hesitation in the patient's subsequent talk (see sequence B). The indistinct "continuer" forces the patient to reconsider what she was telling and to plan her utterance again.

\section{Sequence B}

$210 \mathrm{P}:<\mathrm{Mh}>(.) \mathrm{mhm}(-)$ erm (--) there was a dream series that I had (--) in fact I 211 always had to run away (.) away from something like something threatening 212 me. $\mathrm{h}(-)$

213 T: ${ }^{\circ} \mathrm{mhm}^{\circ}$

214 P: and always it was only somehow dark and it was al (-) always supposedly

215 always at night (---) .h and eventually I have

216 [alone]

217 T: [when was that?] when was that dream series?

218 P: well I think it lasted quite long but it happened (-) seldom ${ }^{\circ}$ well maybe ${ }^{\circ}$ about

219 (.) I don't know every few months it

220 [mostly like]

221 T: [as a child already?] or now as an adult

222 P: well I can’t really say ${ }^{\circ}$ and $^{\circ}(-)$ ((coughs)) but I remember I only know (-) that

223 erm two hh (-) don't know erm I estimate maybe around two thousand-

224 three, two thousand-four, two thousand-five

225 T: $\mathrm{mhmh}$

One difference to the findings of Bergmann and Peräkylä is that the therapist does not wait until the patient comes to an end and then asks questions. In this CBT the therapist asks two questions (line $217 \& 221$ ) before the patient finishes her dream telling and the questions do not relate to the dream story itself. Speaking with Heritage these are ancillary questions that do not align or affiliate with the first speaker. Nevertheless, by 
inquiring about the dream subject the therapist sets the subject itself relevant for the interaction. She up-grades the relevance of the dream subject by questions connected to dreaming. Thus the dream subject becomes something expectable for the psychotherapeutic setting. In the ongoing therapeutic conversation, the patient tells that she could figure out that she was chased by a man. Due to her self-defence training in her real life she managed to beat him down in the dream. Finally, the dream series stopped. Unluckily, it returned last night and this is what she tells the therapist (Sequence C).

\section{Sequence C}

248 P: now I cannot remember the face and nothing else but actually (.) erm (--) and

249 somewhere I was to be killed somehow in this [dream]

250 T: $\left[{ }^{\circ} \mathrm{mh}\right]$

251 P: with a scarf (-) .h somehow I was to be suffocated with that=

$252 \mathrm{~T}:{ }^{\circ} \mathrm{mhmh}^{\circ}=$

253 P: =put around my mouth or around my nose (-) pressed (-) very tight .hh

$254 \mathrm{~T}:{ }^{\circ} \mathrm{hmhm}^{\circ}$

255 P: well this is as much I can remember

$256 \quad(---)$

257 T: e::r (-) was it already around your mouth?

258 P: yes

259 (.)

260 T: aham

The patient narrates the dream and the therapist receives the telling with interjections (lines 250/252/254). With the ancillary question (line 257) the therapist up-grades the relevance for dream-telling and the dream itself. This leads the patient to present a childhood memory. A memory she has regarding the chasing and the man: She remembers a neighbour sneaking around their garden and her mother screaming nervously "there he is again!". The therapist receives that memory recall with information tokens (interjections). After this association the therapist takes over the turn (Sequence D).

\section{Sequence D}

296 T: .H (-) $\mathrm{mh} \mathrm{h} \mathrm{(-)} \mathrm{mh}(--)$ do you have any other (.) ideas about those dreams or

297 knowledge (.) so to speak coping (--) how did your family cope with it

298 in the past (--) and=

299 P: =well I never really told this

300 T: hmhm

$301 \quad(--)$

302 P: I thought (.) my family would say it is something inscrut[able like (.)

303 T:

304 P: why it is like that

$305 \quad$ (1)

306 T: hmhm and did you read anything related

$307 \quad(1.2)$

308 P: HMHM: .h (--) e::r nope (-) I just have

$309 \quad(---)$

310 T: hh

Language and Psychoanalysis, 2016, 5 (2), 19-26 
The therapist starts with delays: inhaling, interjections (line 296). We know from dispreferred answers that they need some preparation in the hearer's ear (Goodwin \& Heritage, 1990). The therapist does not defer to the memory recall but uses this notion to ask for more ideas. By doing so, she slightly downgrades the former recall as 'not sufficient' and has a slight raise in pitch at the word "any other" (in the German transcript the word "noch", line 296), as it is observed in practices of mitigating a message in a more friendly manner. As described for nurses' or doctor's talk with patients we can observe the same style of question here (Depperman \& Spranz Fogasy, 2011). The therapist displays herself as agent of the exploration - she asks questions around the subject. These questions explore the dream subject and thereby upgrade dreams as relevant for psychotherapy and for the interaction. At the same time the therapist downgrades the dream telling by sidestepping the dream-content itself. She continues inquiring about dreams and explores the patient's stance towards dreaming. Sequence E is just one example out of seven.

\section{Sequence $\mathbf{E}$}

362 T: tzs ((klick of the tongue)) .hh (-) \#m\# (---) how is it if you listen in your inner

363 self. what does dreaming mean to

364 2.7)

365 P: well it is somehow like (--) this su subconscious [I think after all

366 T: [hmhm

$367 \quad(1)$

368 P: and everything else one cannot (--) understand [or not

369 T: [hmhm

370 P: grasp as well

371 T: hmhm

372 P: why why for one cannot get access to while (.) living consciously

373 T: yes

374 P: or thinking consciously

The therapist continues asking (lines 362-363) and, therefore, up-grades the subject dream-telling and explores the patient's stance turn by turn. The questions remind on an interrogative style that explore the patient's attitude towards dreams and encourage the patient to take her stance. The patient perceives dreams as something relevant coming from the "subconscious" (line 365) and that dreams reveal things one does not have access to "consciously" (lines 372/374).

\section{An unexpected turn}

After exploring the patient's opinion, inquiring about dreams and, therefore, upgrading the relevance of the dream subject, something unexpected happens: the therapist reveals her own opinion about dreams:

\section{Sequence $\mathbf{F}$}

399 T: Yes (1.7) ((klick of the tongue)) (-) Dreams

$400 \quad(2.1)$

401 T: .hh (--) honestly I have to say to you I don't (-) actually I don't know about it 402 P: $\mathrm{mhm}$ 
$403 \quad(---)$

404 T: ((klick of the tongue)) .hh (--) erm (1) nevertheless I have an attitude towards it

405 anyway

$406 \quad(-)$

$407 \quad$ P: $\mathrm{mhmh}$

$408 \quad(-)$

This is what the behavioural psychologist J. Montangero (2009) writes precisely: "Whenever a patient reports a dream to a CBT therapist, the latter can only politely mention that $\mathrm{s} /$ he does not know what to do with it." (p. 240). In the ongoing talk the therapist proceeds to explain her attitude towards dreams. Due to space the sequences will be skipped. What she does is, she builds her arguments along the previous patient's statements. She defines her opinion in contrast to the patient's previous stance. By that she not only down-grades the relevance of dreams but also the patient's stance. She articulates her opinion about the uncertainty and, thus, uselessness of dreams. Obviously, her opinion opposites the patient's stance.

Now again, something unexpected happens. The patient tells another dream. She tells the dream shown at the beginning. Please turn back to the very first sequence $\mathrm{X}$ and read it again!

\section{The Dream as an Allusion}

Bergmann (2000) wrote that the display of a story is always shaped by its situational circumstances. Researchers on interaction agree that with in an interaction there is more conveyed than just the words we hear. According to the psychoanalytic dream theory a dream can be a reference to the therapeutic relationship. Reading this and taking into account the knowledge from the conversational trajectory this dream is a pictorial display of the current situation. It is an answer to the therapist's sudden down-grading of the dream-telling subject. By the therapist the subject of dream-telling was set to be relevant within the shown Sequences B - F. Due to the sudden and unexpected down-grading the expectations for the further leading conversation should change tremendously. The sudden turn in the conversation can be understood by the phenomenon Freud called "Nachträglichkeit" or "Afterwardsness." This means: Only by the subsequent connection of two or more events under a new sense of recognition, something can appear to be shocking or traumatising. As we have seen the patient shared highly subjective beliefs with the therapist and (i) literally "burned (her) hands" (line 451) at the therapist. In German there is a common saying that somebody burned his fingers after a failed approach to succeed in something. Further, (ii) the patient took the risk to make herself vulnerable - in German we say to get naked when revealing personal issues - while (iii) seeking for help only to find herself in front of a therapist that (iv) looked at her (by exploring questions) and finally (v) dismisses to help her ("one cannot even help me now", line 456). The therapist treats this dream not exactly like an allusion, as Schegloff (1996) suggests it. Nevertheless, she treats the situation as a rupture (Safran, Muran \& Shaker 2014) and tries to repair it by telling a "I-am-like-you-experience" in form of a self-disclosure about a dream she had herself. By revealing her own experience, she tries to restore a trustful relationship and tries to repair the disbalance that appeared due to the revealing stories told by the patient. 


\section{Conclusion}

A general difference between CBT and psychoanalysis is that the latter has a solid dreamtheory. CBT lacks such theory, however, there are a small amount of contributions to proposals how to treat dreams in psychotherapy (Beck, 2002; Hill et al., 2003, Montangero, 2009). As Bergmann and Peräkylä $(2014,2016)$ showed in psychoanalytic encounters the therapist asks about the dream content and, in comparison, in the former analysed CBT session, the therapist uses ancillary questions mainly in order to sidestep the dream-telling. In psychoanalysis post-dream discussion relate the dream to other subjects and, similarities between the dream experience and the everyday experience are pointed out (Bergmann \& Peräkylä, 2014). In this CBT example post dream-discussions focused on dreaming in general and the therapist finally down-grades the dream narratives. In psychoanalysis dream narratives are up-graded (Bergmann \& Peräkylä, 2016). We could also observe that the CBT therapist acts as agent of the conversation whereas in psychoanalysis the patient takes the initiative of talking. I want to stress the attitude in order to avoid misconception that this example is not chosen due to a bias towards CBT. It is solely chosen due to its unique phenomenon of a dream that can only be understood by taking into account the previous conversation. This example can provide clinicians to pay attention towards differing attitudes between them and their patients. It may be of relevance how therapists react to patient's project formulations, which means to pay attention to their ideas of what might be relevant for the psychotherapeutic process of the "talking cure" (Freud, 1895d). Hopefully, I could show that the clinical practice can benefit from conversation analysis if we use it in order to follow conversational trajectories and trace its effects. I hope to make plausible that a dream narrative can be told as a display of a contaminated talk (Jefferson und Lee, 1981) or a disappointment in the therapist. I would like to encourage the idea to study other dreams on this behalf. Or maybe even other stories told within a psychotherapeutic interaction. Due to the appearance of the dream as a pictorial display of the contaminated talk I would like to propose the assumption that dreams may not only be interpreted but that dream narratives sometimes are the interpretation of a current interactional event itself.

\section{Author's Biography}

Marie-Luise Alder, research assistant at International Psychoanalytic University Berlin in the CEMPP Project: Conversation Analysis on Empathy in Psychotherapy Process Research. Doctoral student at Humboldt University Berlin.

\section{Acknowledgement}

I would like to thank Michael B. Buchholz for all helpful remarks during my research process and encouraging me to publish and discuss it in public. And thanks to Laura Cariola for English corrections. 


\section{References}

Beck, A. T. (2002). Cognitive patterns in dreams and daydreams. Journal of Cognitive Psychotherapy, 16, 23-27.

Bergmann, J. (2000). Traumkonversation. In B. Boothe (Ed.), Der Traum - 100 Jahre nach Freuds Traumdeutung (pp. 41-57). Zürich, Switzerland: Hochschulverlag an der ETH.

Bergmann, J. \& Peräkylä, A. (2014). Dealing with dreams in psychoanalysis. The 7th International Conference on Conversation Analysis and Psychotherapy in Ghent, in September. Unpublished paper presentation.

Bergmann, J. \& Peräkylä, A. (2016). Agency and knowledge in the telling and interpretation of dreams in psychoanalytic interaction. The 8th International Conference on Conversation Analysis and Psychotherapy in Helsinki, in June. Unpublished paper presentation.

Buchholz, M. B., \& Reich, U. (2015). Dancing insight. How a psychotherapist uses change of positioning in order to complement split-off areas of experience. Chaos and Complexity Letters, 8, 121-146.

Deppermann, A. \& Spranz-Fogasy, T. (2011). Doctors' questions as displays of understanding. Communication \& Medicine, 8, 111-122.

Freud, S. (1895d). Studies on hysteria. Standard Edition 2.

Goodwin, Charles; Heritage, John (1990). Conversation analysis. Annual Review Anthropology, 19, 283-307.

Hill, C. E., Rochlen, A. B., Zack, J. S., McCready, T., \& Dematatis, A. (2003). Working with dreams using the Hill cognitive-experimental model. A comparison of computer-assisted, therapist empathy, and therapist empathy + input conditions. Journal of Counseling Psychology, 50, 211-220.

Jefferson, Gail; Lee, John R.E. (1981). The rejection of advice. Managing the problematic convergence of a 'trouble-telling' and a 'service encounter'. Journal of Pragmatics, 5, 399-422.

Mathys, H. (2011). Wozu werden Träume geträumt? Interaktive und kommunikative Funktionen von Traummitteilungen im psychoanalytischen Behandlungssetting. Gießen, Germany: Psychosozial-Verlag.

Montangero, J. (2009). Using dreams in cognitive behavioral psychotherapy. Theory, method, and examples. Dreaming, 19, 239-254.

Peräkylä, A., Antaki, C., Vehviläinen, S., \& Leudar, I. (2008). Conversation analysis and psychotherapy. Cambridge, UK: Cambridge University Press.

Sacks, H. \& Jefferson, G. (1995). Lectures on conversation. Volume 2. Oxford, UK: Blackwell.

Safran, J. D., Muran, J. C., \& Shaker, A. (2014). Research on therapeutic impasses and ruptures in the therapeutic alliance. Contemporary Psychoanalysis, 50, 211-232.

Schegloff, E. A. (1996). Confirming allusions. Toward an empirical account of action. American Journal of Sociology, 102, 161-216.

Sidnell, J. \& Stivers, T. (Eds.) (2013). The handbook of conversation analysis. Chichester, UK: Wiley-Blackwell.

Voutilainen, L., Peräkylä, A., \& Ruusuvuori, J. (2011). Therapeutic change in interaction. Conversation analysis of a transforming sequence. Psychotherapy Research, 21, 348-365. 